\title{
Clinical characteristics and outcomes of patients with acute myelogenous leukemia admitted to intensive care: a case-control study
}

\author{
Amanda L Roze des Ordons ${ }^{1}$, Kris Chan², Imran Mirza ${ }^{3}$, Derek R Townsend ${ }^{4}$, Sean M Bagshaw ${ }^{4 *}$
}

\begin{abstract}
Background: There is limited epidemiologic data on patients with acute myelogenous (myeloid) leukemia (AML) requiring life-sustaining therapies in the intensive care unit (ICU). Our objectives were to describe the clinical characteristics and outcomes in critically ill AML patients.

Methods: This was a retrospective case-control study. Cases were defined as adult patients with a primary diagnosis of AML admitted to ICU at the University of Alberta Hospital between January $1^{\text {st }} 2002$ and June $30^{\text {th }}$ 2008. Each case was matched by age, sex, and illness severity (ICU only) to two control groups: hospitalized AML controls, and non-AML ICU controls. Data were extracted on demographics, course of hospitalization, and clinical outcomes.
\end{abstract}

Results: In total, 45 AML patients with available data were admitted to ICU. Mean (SD) age was 54.8 (13.1) years and $28.9 \%$ were female. Primary diagnoses were sepsis (32.6\%) and respiratory failure (37.3\%). Mean (SD) APACHE ॥ score was 30.3 (10.3), SOFA score 12.6 (4.0) with 62.2\% receiving mechanical ventilation, 55.6\% vasoactive therapy, and $26.7 \%$ renal replacement therapy. Crude in-hospital, 90-day and 1-year mortality was $44.4 \%, 51.1 \%$ and $71.1 \%$, respectively. AML cases had significantly higher adjusted-hazards of death ( $H R$ 2.23; 95\% Cl, 1.38-3.60, $p=0.001$ ) compared to both non-AML ICU controls (HR 1.69; $95 \% \mathrm{Cl}, 1.11-2.58, \mathrm{p}=0.02)$ and hospitalized AML controls (OR 1.0, reference variable). Factors associated with ICU mortality by univariate analysis included older age, AML subtype, higher baseline SOFA score, no change or an increase in early SOFA score, shock, vasoactive therapy and mechanical ventilation. Active chemotherapy in ICU was associated with lower mortality.

Conclusions: AML patients may represent a minority of all critically ill admissions; however, are not uncommonly supported in ICU. These AML patients are characterized by high illness severity, multi-organ dysfunction, and high treatment intensity and have a higher risk of death when compared with matched hospitalized AML or non-AML ICU controls. The absence of early improvement in organ failure may be a useful predictor for mortality for AML patients admitted to ICU.

\section{Background}

Acute myelogenous (myeloid) leukemia (AML), a hematologic malignancy characterized by clonal proliferation of myeloblasts, is the most common type of leukemia in adults and uniformly fatal without treatment [1]. Over the past 20 years, more aggressive chemotherapeutic regimens, availability of bone marrow transplantation

\footnotetext{
*Correspondence: bagshaw@ualberta.ca

${ }^{4}$ Division of Critical Care Medicine, Faculty of Medicine and Dentistry, University of Alberta Hospital, 8440-112ST NW, Edmonton, Alberta, T6G2B7 Canada

Full list of author information is available at the end of the article
}

(BMT), and development of subtype-directed therapies have led to improved survival [2]. However, these more aggressive therapeutic strategies have also contributed to a higher likelihood of complications [3,4], translating into a greater demand for support in an intensive care unit (ICU) setting [5-10]. Moreover, ICU support of these patients has been associated with more intensive and greater resource utilization [11].

A number of observational studies in patients with hematologic malignancies admitted to ICU have described the clinical outcomes and prognostic factors for survival $[5-8,11-22]$. The majority of studies have

\section{() Biomed Central}


been small, single centre, retrospective cases-series and have enrolled a mixed cohort of critically ill patients with all forms of hematologic malignancy or who had received a BMT.(Additional File 1) Few studies have specifically investigated the ICU course in AML patients $[13,14,16,17]$. Two primarily focused on AML patients with pulmonary infiltrates requiring mechanical ventilation, and reported a dismal ICU survival of 3-13\% $[14,17]$. In another study of 83 consecutive AML patients, Rabbat et al reported 66\% ICU survival and $33 \%$ 1-year survival [13]. In a cohort of 90 consecutive patients admitted to ICU over 3-year surveillance, of which $82 \%$ had a primary AML diagnosis, Thakkar et al described poor 6 and 12 month survival of only $18 \%$ and $16 \%$, respectively [16]. Finally, Park et al described $68 \%$ hospital mortality in 50 acute leukemia patients, $70 \%$ with AML, admitted to ICU with septic shock [16]. However, clear inferences regarding prognosis for critically ill AML patients from these studies are limited due to selection bias (i.e. only receiving mechanical ventilation), inclusion of a mixed leukemia population (i.e. acute lymphoblastic leukemia), or lack of controls for comparison.

Accordingly, we performed a retrospective case-control study of patients with AML admitted to ICU. We hypothesized that AML patients receiving ICU support would have higher mortality when compared with matched controls; however, that a considerable proportion of these AML patients would survive to leave hospital. Our objectives were to: 1 ) define the incidence of ICU admissions with a primary diagnosis of AML; 2) describe the clinical characteristics, course and treatment intensity of ICU admissions with AML; and 3) describe the short- and long-term outcomes of ICU AML patients compared with matched non-AML ICU patients and non-ICU AML hospitalized patients.

\section{Methods}

\section{Study Design, Setting and Population}

We performed a retrospective case-control study of patients with acute myelogenous (myeloid) leukemia (AML) admitted to the General Systems Intensive Care Unit (GSICU) at the University of Alberta Hospital between January $1^{\text {st }}, 2002$ and June $30^{\text {th }}, 2008$. Cases were defined as adult patients (age $\geq 18$ years) with a confirmed diagnosis of AML and admission to the GSICU. Each case was then matched with two control groups: 1) non-ICU hospitalized patients with confirmed AML (i.e. admitted to the medical/hematology ward; matched 1:1); and subsequently to 2) non-AML critically ill patients (i.e. admitted to the GSICU; matched 1:5). The study protocol was approved by the Health Research Ethics Board at the University of Alberta prior to commencement.

\section{Study Definitions}

AML diagnosis was typed and characterized according to the WHO and FAB classification schemes [23]. The status of AML was categorized as: newly diagnosed/ active, refractory or relapse, in remission following HSCT, or in remission. AML patients were also classified according to treatment regimen received: intensive induction/consolidative chemotherapy, or cytoreductive chemotherapy and/or palliation. Patients receiving induction/consolidative chemotherapy for AML at our institution do not routinely receive prophylactic antibiotic or antifungal therapy. Neutropenia was defined as an absolute neutrophil count $<1.0 \times 10^{9}$ cells $/ \mathrm{L}$. When patients develop an episode of febrile neutropenia (i.e. documented temperature $\geq 38.3^{\circ} \mathrm{C}$ and ANC $\leq 1.0$ cells/ $10^{9}$ ) empiric broad-spectrum antimicrobials are initiated. The presence of co-morbid illness was determined and quantified. Non-AML leukemia, lymphoma or solid organ tumor were defined by confirmatory pathologic investigations. Congestive heart failure (CHF) was defined as the presence of New York Heart Association (NYHA) class III or IV disease. Chronic lung disease was defined as functional limitation or home oxygen therapy attributable to documented lung pathology. Chronic kidney disease (CKD) was defined as National Kidney Foundation Kidney Disease Outcome Quality Initiative (KDIGO) $\geq$ stage 4 disease. Liver disease was defined as biopsy proven cirrhosis or elevated liver enzymes attributable to active liver disease. Human immunodeficiency virus (HIV) or acquired immunodeficiency syndrome (AIDS) were defined by documented HIV status and/or documented opportunistic infection/ illness attributable to HIV. Shock was defined by a documented mean arterial pressure (MAP) $\leq 60 \mathrm{mmHg}$ and/or use of vasoactive therapy and an elevated serum lactate. Illness severity was defined according to the Acute Physiology and Chronic Health Evaluation (APACHE) II score [24]. Baseline and changes to organ failure were characterized by the Sequential Organ Failure Assessment (SOFA) score [25]. Acute kidney injury (AKI) was defined as an acute rise in serum creatinine $\geq 150 \mu \mathrm{mol} / \mathrm{L}$ or urine output $\leq 400 \mathrm{~mL} / 24 \mathrm{hr}$ and no documented CKD ( $\geq$ stage 4 ).

\section{Study Protocol}

Cases were identified by review of a local database of consecutive new diagnoses of AML maintained by the Department of Laboratory Medicine at the University of Alberta Hospital. This database maintains detailed data on the clinical and diagnostic characteristics of AML patients (i.e. WHO classification, cytogenetic profile, laboratory values at diagnosis). These AML patients were subsequently cross referenced with an ICU-specific database, the Minimal Data Set (MDS) database, which 
routinely captures demographic, clinical, physiologic and outcome data on all GSICU admissions. The linkage of these two datasets enabled capture of "cases" of confirmed AML and GSICU admission. Each case was subsequently matched to the two control groups. NonICU hospitalized AML controls were randomly selected from the AML database and matched for age ( \pm 2 years) and sex. Non-AML ICU controls were randomly selected from the MDS dataset, and matched for age ( \pm 2 years), sex and APACHE II score ( \pm 2 points) (ICU cohort only).

Detailed data pertaining to demographics, clinical characteristics, acute physiology, course in hospital, and clinical outcomes were extracted from the medical records of each patient and merged with data obtained from the AML and MDS databases. Demographic and baseline clinical data included age, sex, co-morbid disease, primary diagnosis, surgical status, and dates of hospital/ICU admission and discharge. The characteristics of AML were extracted from the AML database. For cases and ICU controls, acute physiologic data, laboratory parameters, and clinical course, interventions, including corticosteroids, AML-specific chemotherapy, vasoactive therapy, mechanical ventilation and renal replacement therapy (RRT) were recorded. SOFA scores were ascertained at baseline and at days 1, 3 and 7 after ICU admission.

The primary outcome of interest was the incidence of ICU admissions for patients with a diagnosis of AML, defined as a proportion (number of cases per number of individual admissions) and as number of cases per 1000 ICU admissions. For patients with more than one ICU admission within the same hospitalization, only the first ICU episode was considered. Secondary outcomes of interest included short-term (ICU/hospital) and longterm (90-day, 1-year) survival, ICU/hospital lengths of stay, changes in organ failure scores during the first week in ICU (i.e. $\triangle$ SOFA), and measures of treatment intensity (i.e. need for mechanical ventilation, vasoactive therapy, and RRT). Tertiary outcomes included determination of factors associated with survival to discharge from ICU.

\section{Statistical Analysis}

Clinical variables and univariate comparison between groups are reported as means with standard deviations (SD) for normally or near normally distributed variables and compared using Student's t-test or analysis of variance (ANOVA); non-normally distributed continuous data is reported as medians with inter-quartile ranges (IQR) and compared using Mann Whitney $U$ test or Kruskal Wallis test, as appropriate. Categorical data are reported as proportions and compared using Fisher's Exact Test. Crude survival stratified by study group was assessed graphically by the Kaplan-Meier product limit estimator and compared with the log-rank test. Cox proportional hazards analysis was used to evaluate the association between AML cases and controls and mortality. Data are presented as crude and covariateadjusted hazard ratios (HR) and 95\% confidence intervals $(\mathrm{CI})$. Plots of $\log (-\log$ [survival]) versus $\log$ (survival time) were constructed to evaluate the assumption of proportionality. Univariate analysis of AML cases was performed to evaluate for clinical factors associated with ICU survival. Intercooled Stata Release 10.2 (Stata Corp, TX) was used for all data analysis. A p-value of $<0.05$ was considered statistically significant for all comparisons.

\section{Results}

The baseline demographics and clinical features of patients stratified by group are shown in Table 1 . There were 386 patients diagnosed with AML during the study period. A total of 50 AML patients, representing $13 \%$ of all new AML diagnoses, were admitted to ICU. This represented an estimated incidence of $0.74 \%$ of all ICU admissions $(\mathrm{n}=6,801)$ or 7.4 AML patients per 1000 ICU admissions. The medical records for five of these AML ICU patients could not be retrieved for detailed review; therefore, these patients were omitted from further analysis.

\section{Demographic, Clinical and Diagnostic Characteristics of AML}

AML cases had a mean (SD) age of 54.8 (13.1) years, $28.9 \%$ were female, and had a median (IQR) one $(0-2)$ co-morbid illness (Table 1). There were no statistical differences in the AML classification, cytogenetic profile or therapeutic regimen between AML cases and controls (Table 2). There were more AML cases classified as remission when compared with AML controls. Of these, four had received HSCT after intensive chemotherapy. The median (IQR) duration from AML diagnosis to ICU admission was 46 days (12-251). This duration was shortest in newly diagnosed or those with active disease (17 days [2-28]) and in those in remission post-HSCT (93 [88-964]) compared to those with refractory/ relapsed disease (323 [144-743]) or remission following chemotherapy alone $(280[102-436])(p=0.0001)$.

\section{Baseline Characteristics, Physiology and Laboratory Parameters in ICU}

AML cases, when compared to ICU controls, had a higher rate of admission for sepsis and a non-significant but higher rate for respiratory failure (Table 3). Only one AML case $(2.2 \%)$ was post-operative, compared with $23.6 \%$ of ICU controls $(\mathrm{p}<0.001)$. As expected, there was no significant difference in mean (SD) APACHE II 
Table 1 Summary of baseline demographic and clinical features of patients stratified by group

\begin{tabular}{|c|c|c|c|c|c|}
\hline Variable & $\begin{array}{c}\text { Total } \\
(\mathrm{n}=320)\end{array}$ & $\begin{array}{l}\text { AML ICU Cases } \\
(n=45)\end{array}$ & $\begin{array}{l}\text { AML non-ICU Controls } \\
(n=50)\end{array}$ & $\begin{array}{l}\text { Non-AML ICU Controls } \\
(n=225)\end{array}$ & p-value \\
\hline Age (mean [SD]) (years) & $54.6(13.7)$ & $54.8(13.1)$ & $53.4(16.2)$ & $54.8(13.2)$ & 0.75 \\
\hline Female sex (\%) & $91(28.4)$ & $13(28.9)$ & $11(22.0)$ & $67(29.8)$ & 0.56 \\
\hline BMI (mean [SD]) $\left(\mathrm{kg} / \mathrm{m}^{2}\right)$ & $29.3(7.1)$ & $30.7(6.6)$ & $29.8(6.4)$ & $27.0(7.9)$ & 0.13 \\
\hline \multicolumn{6}{|l|}{ Co-morbid disease type (\%) } \\
\hline Leukemia & $102(31.9)$ & $45(100)$ & $50(100)$ & $7(3.1)$ & $<0.001$ \\
\hline Lymphoma & $5(1.6)$ & $2(2.2)$ & $0(0)$ & $4(1.8)$ & 0.81 \\
\hline Solid organ tumor & $8(2.5)$ & $1(2.2)$ & $0(0)$ & $7(3.1)$ & 0.64 \\
\hline Congestive heart failure & $11(3.4)$ & $1(2.2)$ & $3(6.0)$ & $7(3.1)$ & 0.62 \\
\hline Chronic lung Disease & $16(5.0)$ & $0(0)$ & $3(6.0)$ & $13(5.8)$ & 0.28 \\
\hline Chronic kidney disease & $19(5.9)$ & $0(0)$ & $2(4.0)$ & $17(7.6)$ & 0.13 \\
\hline Liver disease & $41(12.8)$ & $1(2.2)$ & $2(4.0)$ & $38(16.9)$ & 0.002 \\
\hline HIV/AIDS & $5(1.6)$ & $0(0)$ & $1(2.0)$ & $4(1.8)$ & 1.0 \\
\hline \multicolumn{6}{|l|}{ Co-morbid disease (\%)" } \\
\hline None (\%) & $143(44.7)$ & $24(53.3)$ & $0(0)$ & $119(52.9)$ & $<0.001$ \\
\hline 1 & $149(46.6)$ & $19(42.2)$ & $41(82.0)$ & 89 (39.6) & \\
\hline 2 & $26(8.1)$ & $2(4.4)$ & $7(14.0)$ & $17(7.6)$ & \\
\hline$\geq 3$ & $2(0.6)$ & $0(0)$ & $2(4.0)$ & $0(0)$ & \\
\hline Surgical admission (\%) & $54(16.9)$ & $1(2.2)$ & $0(0)$ & $53(23.6)$ & $<0.001$ \\
\hline
\end{tabular}

Abbreviations: $\mathrm{BMI}=$ body mass index; HIV = human immunodeficiency virus; AIDS = acquired immunodeficiency syndrome.

$\S$ Included prior myocardial infarction, congestive heart failure, and/or peripheral vascular disease.

I Co-morbid disease excluding AML diagnosis.

scores at ICU admission $(\mathrm{p}=0.39)$ (Table 3$)$. AML cases had a lower GCS score $(\mathrm{p}=0.0003)$, higher temperature $(\mathrm{p}=0.05)$, higher heart rate $\mathrm{p}=0.001)$, and respiratory rate $(\mathrm{p}<0.0001)$ when compared with ICU controls.

Treatment Intensity and Course in ICU for AML patients AML cases were significantly less likely to receive mechanical ventilation $(\mathrm{p}=0.003)$ despite comparable or low $\mathrm{PaO}_{2} / \mathrm{FiO}_{2}$ ratios. Of AML cases, $88.4 \%$ presented with shock, and $75.6 \%$ were supported with vasoactive therapy. Acute kidney injury occurred in $53.5 \%$ with $47.8 \%$ of these patients subsequently receiving support with acute RRT. In total, $97.8 \%$ received broad-spectrum antimicrobials, $86.7 \%$ received transfused blood products, $48.9 \%$ received replacement corticosteroids, $51.2 \%$ received G-CSF and $15.6 \%$ received AML-specific chemotherapy while in ICU. At the time of ICU admission, 93.3\% were designated as full resuscitation, however, $47.6 \%$ later had their status changed to not for resuscitation (NFR) while in ICU. Of the 17 ICU deaths in AML patients, 88.2\% occurred in those with a change in NFR status ( $p<0.0001$ compared with ICU mortality for no change in NFR status).

\section{Survival, Lengths of Stay and Discharge Disposition}

Crude survival at hospital discharge, 28-days, 90-days and 1-year was lower for AML cases compared with both
AML and ICU controls (Table 4, Figure 1). At 1-year, survival among AML cases was $28.9 \%$, compared with $52.0 \%$ and $54.0 \%$ for AML and ICU controls, respectively $(\mathrm{p}=0.03)$. The median survival for AML cases admitted to ICU was 82 days (95\% CI, 14-700), and was significantly lower than for AML and ICU controls (Table 4). By Cox survival analysis, AML cases had a significantly higher adjusted-hazards ratio (HR) for death (HR 2.23; 95\% CI, 1.38-3.60) compared with both ICU (HR 1.69; 95\% CI 1.11-2.58) and AML controls (HR 1.0, reference) (Table 5). ICU and hospital stay were non-significantly longer for AML cases surviving to ICU and hospital discharge (Table 5). In total, $46.7 \%$ of AML cases survived hospitalization and were discharged home compared with $40.9 \%$ of ICU controls $(p=0.32)$ and $62.0 \%$ of AML controls $(\mathrm{p}=0.15)$. By Cox survival analysis, the adjusted-HR of death, conditional on survival to hospital discharge, was significantly higher for AML cases (HR 2.46; 95\% CI, 1.4-4.3, $\mathrm{p}=0.002$ ) compared to either AML controls (HR 1.40; 95\% CI, 0.85-2.30, p = 0.19) or ICU controls (HR 1.0, reference).(Figure 2).

\section{Prognostic Factors for AML Patients in ICU}

For AML cases, several factors were found to be associated with ICU mortality by univariate analysis (Table 6 Older age, AML subtype M1, higher organ failure score, shock, vasoactive therapy, mechanical ventilation were all 
Table 2 Summary of diagnostic characteristics of AML

\begin{tabular}{|c|c|c|c|c|}
\hline Variable & $\begin{array}{c}\text { Total } \\
(\mathrm{n}=95)\end{array}$ & $\begin{array}{l}\text { AML ICU Cases } \\
\quad(n=45)\end{array}$ & $\begin{array}{l}\text { AML non-ICU Controls } \\
(n=50)\end{array}$ & p-value \\
\hline \multicolumn{5}{|l|}{ AML WHO classification $(n=91)$} \\
\hline AML with recurrent genetic abnormalities & $44(46.3)$ & $19(42.2)$ & $25(50.0)$ & 0.18 \\
\hline AML with multi-lineage dysplasia & $17(17.9)$ & $10(22.2)$ & $7(14.0)$ & \\
\hline AML and myelodysplastic syndromes, therapy-related & $6(6.3)$ & $5(11.1)$ & $1(2.0)$ & \\
\hline AML not otherwise categorized & $28(29.5)$ & $11(24.4)$ & $17(34.0)$ & \\
\hline \multicolumn{5}{|l|}{ AML FAB Classification $(n=71)$} \\
\hline Mo & $4(4.2)$ & $0(0)$ & $4(8.0)$ & 0.12 \\
\hline M1 & $28(29.5)$ & $15(33.3)$ & $13(26.0)$ & \\
\hline M2 & $20(21.1)$ & $11(24.4)$ & $9(18.0)$ & \\
\hline M3 & $12(12.6)$ & $3(6.7)$ & $9(18.0)$ & \\
\hline M4 & $12(12.6)$ & $4(8.9)$ & $8(16.0)$ & \\
\hline M4eo & $5(5.3)$ & $4(8.9)$ & $1(2.0)$ & \\
\hline M5 & $13(13.7)$ & $7(15.6)$ & $6(12.0)$ & \\
\hline M6 & $1(1.1)$ & $1(2.2)$ & $0(0)$ & \\
\hline \multicolumn{5}{|l|}{ Cytogenetic prognosis ${ }^{\S}(\%)$} \\
\hline Good & $13(13.7)$ & $6(13.3)$ & $7(14.0)$ & 0.96 \\
\hline Intermediate & $38(40.0)$ & $17(37.8)$ & $21(42.0)$ & \\
\hline Poor & $14(28.0)$ & $13(28.9)$ & $14(28.0)$ & \\
\hline Unknown/not available & $8(16.0)$ & $9(20.0)$ & $8(16.0)$ & \\
\hline \multicolumn{5}{|l|}{ Complete blood count at diagnosis: } \\
\hline Hemoglobin $(\mathrm{g} / \mathrm{L})$ & $96.7(22.1)$ & $95.9(21.6)$ & $97.322 .6)$ & 0.76 \\
\hline Platelets (cells $\left./ 10^{9}\right)$ & $46(26-96)$ & $45(31-96)$ & $47(24-96)$ & 0.46 \\
\hline White cell count (WBC) (cells $/ 10^{9}$ ) & $8.2(2.3-50.6)$ & $7.7(2.0-50.8)$ & $16.0(3.2-42.9)$ & 0.87 \\
\hline WBC $<1(\%)$ & $6(7.1)$ & $3(6.7)$ & $3(6.0)$ & 1.0 \\
\hline WBC > $25(\%)$ & $34(35.8)$ & $15(33.3)$ & $19(38.0)$ & 0.67 \\
\hline Duration of Neutropenia (days) (mean [SD]) & $14.1(14.3)$ & $13.1(14.4)$ & $15.2(14.2)$ & 0.48 \\
\hline Bone marrow blast count (\%) & $56.6(23.7)$ & $52.9(23.7)$ & $60.1(23.5)$ & 0.15 \\
\hline Blasts $>20 \%$ & $86(94.5)$ & $41(93.2)$ & $45(95.7)$ & 0.67 \\
\hline \multicolumn{5}{|l|}{ AML Status } \\
\hline Newly diagnosed/active disease & $58(61.1)$ & $24(53.3)$ & $34(68.0)$ & 0.01 \\
\hline Refractory/relapse & $29(30.5)$ & $13(28.9)$ & $16(32.0)$ & \\
\hline BMT/remission & $4(4.2)$ & $4(8.9)$ & $0(0)$ & \\
\hline Remission & $4(4.2)$ & $4(8.9)$ & $0(0)$ & \\
\hline \multicolumn{5}{|l|}{ Therapeutic Regimen } \\
\hline Intensive/induction chemotherapy & $78(82.1)$ & $38(84.4)$ & $40(80.0)$ & 0.60 \\
\hline Cytoreductive/palliative & $17(17.9)$ & $7(15.6)$ & $10(20.0)$ & \\
\hline
\end{tabular}

Abbreviations: WHO = World Health Organization; FAB = French American British; WBC = white blood cell count.

$\S$ Cytogenetic Prognosis: Good = t(8;21); $\mathrm{t}(15 ; 17)$; inv16 or t(16;16); Intermediate = normal; trisomy 8 ; 11q23 abnormality; Poor = deletion of chromosome 5 or 5q; deletion of chromosome 7 or $7 q ; 3 q$ abnormality; complex; Unknown = significance not known; no cytogenetic information.

associated with lower likelihood of survival. Alternatively, AML patients receiving AML-specific chemotherapy while in ICU had higher survival. The absence of change or worsening in organ failure score in the first three days after ICU admission was also associated with lower survival (Figure 3). In this cohort, no significant association was found between 90-day survival and co-morbid illness, cytogenetic profile, time from AML diagnosis to ICU admission, relapse or refractory AML status, primary septic diagnosis, or RRT.

\section{Discussion}

We conducted a 6.5-year retrospective matched casecontrol study to compare the clinical characteristics, course, and outcomes of patients with AML admitted to ICU compared with non-critically ill hospitalized AML controls and non-AML critically ill controls.

Our data have several relevant findings. First, while AML patients represent only a minority of all ICU admissions, we found that life threatening illness prompting ICU admission is not uncommon, occurring 
Table 3 Summary of ICU admission characteristics, acute physiology, and laboratory parameters stratified by AML status

\begin{tabular}{|c|c|c|c|c|}
\hline Variable & $\begin{array}{c}\text { Total } \\
(n=275)\end{array}$ & $\begin{array}{l}\text { AML ICU Cases } \\
(n=45)\end{array}$ & $\begin{array}{l}\text { Non-AML ICU Controls } \\
\quad(n=225)\end{array}$ & $p$-value \\
\hline \multicolumn{5}{|l|}{ Admission diagnostic category $(\%)^{\S}$} \\
\hline Sepsis/Infectious & $53(19.8)$ & $14(32.6)$ & $39(17.3)$ & 0.04 \\
\hline Respiratory & $70(26.1)$ & $16(37.2)$ & $54(24.0)$ & 0.09 \\
\hline Genitourinary & $7(2.6)$ & $0(0)$ & $7(3.1)$ & 0.60 \\
\hline Gastrointestinal & $50(18.7)$ & $1(2.3)$ & $49(21.8)$ & 0.001 \\
\hline Cardiovascular & $27(10.1)$ & $1(2.3)$ & 26 (11.6) & 0.09 \\
\hline Neurologic & $15(5.6)$ & $2(4.7)$ & $13(5.8)$ & 1.0 \\
\hline Endocrine/Metabolic & $13(4.9)$ & $0(0)$ & $13(5.8)$ & 0.14 \\
\hline Trauma & $22(8.2)$ & $0(0)$ & $22(9.8)$ & 0.03 \\
\hline Other & $11(4.1)$ & $9(20.9)$ & $2(0.9)$ & $<0.001$ \\
\hline APACHE II score (mean [SD]) & $29.1(9.9)$ & $30.3(10.3)$ & $28.9(9.9)$ & 0.39 \\
\hline APACHE II score > $25(\%)$ & $185(68.5)$ & $35(77.8)$ & $150(66.7)$ & 0.16 \\
\hline SOFA score (mean [SD]) & $11.7(4.6)$ & $12.6(4.0)$ & $10.8(4.9)$ & 0.05 \\
\hline SOFA score > $11(\%)$ & $55(57.9)$ & $32(71.1)$ & $23(46.0)$ & 0.02 \\
\hline Mechanical ventilation (\%) & $225(83.3)$ & $30(66.7)$ & $195(86.7)$ & 0.003 \\
\hline \multicolumn{5}{|l|}{ Acute physiology } \\
\hline GCS (mean [SD]) & $7.6(3.4)$ & $5.9(3.4)$ & $7.9(3.3)$ & 0.0003 \\
\hline Temperature $_{\max }($ mean $[S D])$ (degrees C) & $37.4(3.6)$ & $38.4(1.2)$ & $37.2(3.8)$ & 0.05 \\
\hline Heart rate $_{\max }($ mean $[S D])(/ \min )$ & $118(23.4)$ & $128(18)$ & $116(24)$ & 0.001 \\
\hline Respiratory rate $\max _{\text {(mean }[S D])}(/ \min )$ & $28(8)$ & $34(8)$ & $26(8)$ & $<0.0001$ \\
\hline Mean arterial pressure ${ }_{\min }($ mean $[\mathrm{SD}])(\mathrm{mmHg})$ & $59(17)$ & $60(17)$ & $59(17)$ & 0.74 \\
\hline \multicolumn{5}{|l|}{ Laboratory parameters } \\
\hline Hematocrit (mean [SD]) & $26.6(6.7)$ & $22.6(5.0)$ & $27.3(6.7)$ & $<0.0001$ \\
\hline White blood cell count (med [IQR]) $\left(10^{9}\right.$ cells $\left./ \mathrm{mL}\right)$ & $7.8(4.2-13.1)$ & $0.6(0.2-7.5)$ & $9.1(4.8-13.6)$ & $<0.0001$ \\
\hline Bilirubin (med $[\mathrm{IQR}])(\mu \mathrm{mol} / \mathrm{L})$ & $23(14-49)$ & $33(19-48)$ & $22(13-52)$ & 0.26 \\
\hline $\mathrm{PaO}_{2} / \mathrm{FiO}_{2}$ ratio (mean $[\mathrm{SD}]$ ) & $174(97)$ & $158(85)$ & $177(99)$ & 0.22 \\
\hline $\mathrm{pH}$ (mean [SD]) & $7.25(0.15)$ & $7.30(0.13)$ & $7.24(0.15)$ & 0.03 \\
\hline Serum Sodium (mean [SD]) (mmol/L) & $137(6.0)$ & $137(7.0)$ & $137(5.8)$ & 0.63 \\
\hline Serum Creatinine (med [IQR) $(\mu \mathrm{mol} / \mathrm{L})$ & $168(93-284)$ & $145(97-203)$ & $170(89-318)$ & 0.13 \\
\hline Urine output (med [IQR]) (L/24 hr) & $1.3(0.4-2.5)$ & $2.2(1.0-3.1)$ & $1.2(0.4-2.4)$ & 0.0006 \\
\hline Urine output <400 mL (\%) & $61(22.9)$ & $3(7.0)$ & $58(25.9)$ & 0.005 \\
\hline Acute kidney injury (\%) & $138(52.7)$ & $23(53.5)$ & $115(52.5)$ & 1.0 \\
\hline
\end{tabular}

Abbreviations: SOFA = sequential organ failure assessment; APACHE = acute physiology and chronic health evaluation; GCS = Glasgow coma score; ANC = absolute neutrophil count.

§ Sum exceeds $100 \%$ due to more than one primary diagnosis.

in $13 \%$ of all patients with a diagnosis of AML. Second, these critically ill AML patients had predominantly septic and/or respiratory-related diagnoses and exhibited a high acuity of illness, with the majority presenting with shock. Moreover, AML patients had greater severity of organ dysfunction. Third, AML patients were less likely to receive mechanical ventilation; yet overall they received high intensity support that included vasoactive therapy in $75.6 \%$ and RRT in $26.7 \%$, respectively. This translated into longer, though non-significant, stays in ICU and hospital. Fourth, we also found critically ill AML patients had lower adjusted-survival when compared with controls. By univariate analysis, several factors were associated with a lower probability of survival, including older age, AML M1 subtype, higher baseline SOFA score, presence of shock, vasoactive therapy and mechanical ventilation. We also found that worsening SOFA score early after ICU admission correlated with lower survival. Alternatively, receipt of AML-specific chemotherapy while in ICU correlated with higher survival. Finally, changes in patient resuscitation status (i.e. to NFR) and withdrawal of support were both significantly associated with higher likelihood of death at 90-days. 
Table 4 Summary of clinical outcomes stratified by group

\begin{tabular}{|c|c|c|c|c|c|}
\hline Outcome & $\begin{array}{c}\text { Total } \\
(n=145)\end{array}$ & $\begin{array}{l}\text { AML ICU Cases } \\
(\mathrm{n}=45)\end{array}$ & $\begin{array}{l}\text { AML non-ICU Controls } \\
(n=50)\end{array}$ & $\begin{array}{l}\text { Non-AML ICU Controls } \\
(\mathrm{n}=225)\end{array}$ & p-value \\
\hline ICU death (\%) & $83(30.7)$ & $17(37.8)$ & - & $66(29.3)$ & 0.29 \\
\hline Hospital death (\%) & $121(37.8)$ & $20(44.4)$ & $9(18.0)$ & $92(40.9)$ & 0.004 \\
\hline 28-Day death (\%) & $98(30.6)$ & $17(37.8)$ & $8(16.0)$ & $73(32.4)$ & 0.03 \\
\hline 90-Day death (\%) & $132(41.3)$ & $23(51.1)$ & $16(32.0)$ & $93(41.3)$ & 0.17 \\
\hline 1-Year death (\%) & $178(55.6)$ & $32(71.1)$ & $27(54.0)$ & $119(52.9)$ & 0.08 \\
\hline ICU length of stay (days) & $4(2-11)$ & $5(2-12)$ & - & $4(2-11)$ & 0.38 \\
\hline Survived & $5(2-12)$ & $8(2-14)$ & - & $5(3-11)$ & 0.44 \\
\hline Dead & $2(1-5)$ & $4(1-7)$ & - & $1(1-3)$ & 0.17 \\
\hline Hospital length of stay (days) & $15(6-39)$ & $22(11-47)$ & $24(9-35)$ & $13(5-36)$ & 0.12 \\
\hline Survived & $21(10-45)$ & $37(18-50)$ & $25(12-35)$ & $17(10-44)$ & 0.22 \\
\hline Dead & $14(9-28)$ & $13(9-19)$ & $6(1-28)$ & $3(1-12)$ & 0.17 \\
\hline Median survival (95\% Cl) (days) & $207(14-2442)$ & $82(14-700)$ & $274(55-1303)$ & $258(9-2442)$ & 0.01 \\
\hline
\end{tabular}

There is a paucity of epidemiological data pertaining to patients with AML requiring life-sustaining measures in the ICU. (Additional File 1) While numerous small series have reported on the clinical outcomes for patients with all forms of hematologic malignancy admitted to ICU, very few have focused on AML, and fewer still have provided estimates of incidence $[13,14,16,17]$. During a 5 -year surveillance, Tremblay et al reported that among 163 consecutive hospitalized AML patients, with a range in AML status (including 38 having received a HSCT), only 32 were admitted to ICU and supported with mechanical ventilation (cumulative incidence 19.6\%) [17]. We observed a lower cumulative incidence, with just over 1 in 10 of all newly diagnosed AML patients being supported in ICU; moreover, we observed that AML patients comprised $<1 \%$ of all ICU admissions during the study period. In a 4-year retrospective study, Merz et al reported on 101 ICU admissions $(\mathrm{n}=84)$ with hematologic malignancies, of which $54.4 \%$ had a diagnosis of AML [11]. These AML

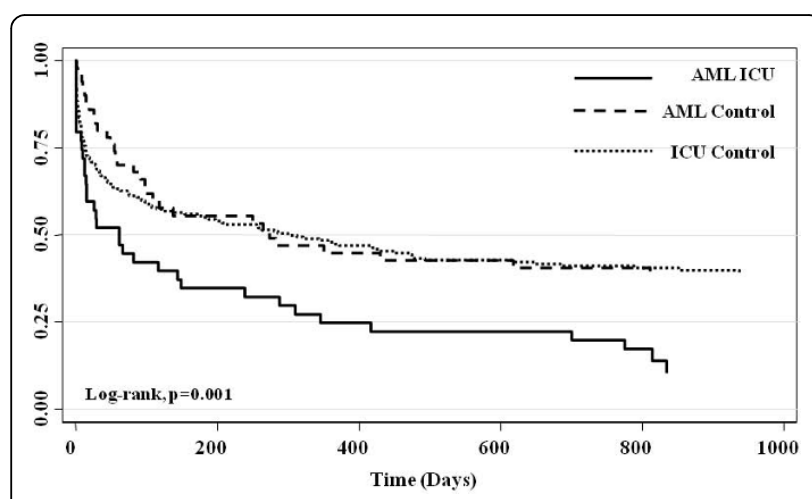

Figure 1 Crude K-M survival estimates by group (truncated at 1000 days). admissions represented approximately $1.4 \%$ of all "emergent and medical" ICU admissions.

Among AML patients admitted to ICU, the in-hospital, 90-day and long-term adjusted-survival were observed to be lower when compared with either hospitalized AML or ICU controls. To our knowledge, this is the first study to evaluate the long-term survival experience of critically ill AML patients compared with matched controls. When compared with an unmatched convenience sample of non-AML critically ill patients, Tremblay et al found AML patients requiring mechanical ventilation to clearly have higher in-hospital mortality [17]. Merz et al found in-hospital mortality noticeably higher for ICU admissions associated with hematologic malignancies compared with unmatched controls $(33.7 \%$ vs. $10.7 \%, \mathrm{p}<0.0001)$ [11]. In general, the observed survival in our study is largely consistent with prior studies, where estimates of ICU, in-hospital and 1-year survival were $12-70 \%, 3-64 \%$, and $0-34 \%$, respectively [12-14,16,17,20,21,26-34]. The median survival of critically ill AML patients in our cohort was only about three months, in contrast to approximately nine months for the control groups. While the majority of deaths in AML patients occurred early after ICU admission (median duration 5 days), the adjusted risk of death remained significantly higher during follow-up compared with either control group. These data would suggest, in general, that AML patients developing an episode of critical illness prompting ICU support have a less favorable outcome compared with hospitalized AML and non-AML ICU patients.

Prior data imply AML patients supported in ICU have greater health resource utilization. This was shown by Merz et al, who described considerably higher ICU resource use by hemato-oncological patients, as measured by the Therapeutic Interventions Scoring System 
Table 5 Cox proportional hazards survival analysis stratified by group

\begin{tabular}{ccc}
\hline Group & $\begin{array}{c}\text { Crude HR } \\
(\mathbf{9 5 \%} \mathrm{Cl})\end{array}$ & $\begin{array}{c}\text { Adjusted }^{\mathbf{5}} \mathbf{H R} \\
\mathbf{( 9 5 \% ~ C l )}\end{array}$ \\
\hline AML controls & $1.0^{\mathbf{9}}$ & $1.0^{\mathbf{9}}$ \\
\hline ICU controls & $1.24(0.84-1.83)$ & $1.69(1.11-2.58)$ \\
\hline AML cases & $2.12(1.31-3.43)$ & $2.23(1.38-3.60)$ \\
\hline
\end{tabular}

Abbreviations: $\mathrm{AML}=$ acute myelogenous leukemia; $\mathrm{ICU}=$ intensive care unit; $\mathrm{Cl}=$ confidence interval.

$\S$ Cox PH model adjusted for: age, sex, co-morbid disease, surgical status.

१ Reference variable.

(TISS) (214 vs. 95, p < 0.0001) and ICU length of stay (2.0 vs. 1.1 days, $\mathrm{p}<0.02$ ), compared with emergent medical ICU patients [11]. Despite no difference in the rates of mechanical ventilation or RRT between groups, both of these interventions showed significant correlation with total ICU resource use. This also translated into greater total direct costs per ICU admission for hemato-oncological patients. While our study did not incorporate a formal cost analysis, AML patients in our study had non-significant, but longer observed stays in both ICU and hospital. Interestingly, our data found significantly fewer AML patients received mechanical ventilation, despite evidence of similar or worst lung injury. This observation may, in part, be attributable to prior data correlating less favorable prognosis for these patients requiring mechanical ventilation $[17,22,28,35]$. These data also suggest greater health resource use for AML patients; however, there is little data on whether this is balanced by higher quality-adjusted survival of ICU admissions with hematologic malignancy. In a small series of 92 critically ill patients with hematologic malignancy, Yau et al described the quality-of-life as acceptable or good in the 7 survivors (7.6\%) at 1-year, with no patient reporting significant limitations to daily activities [34].

Few data have explored the long-term disposition of AML patients after life-threatening critical illness. Interestingly, despite lower overall survival, $46.7 \%$ of all AML patients supported in ICU in our study survived hospitalization to be discharged home (or $84.0 \%$ of survivors). This was statistically comparable to hospitalized AML and ICU controls.

The characterization of potential factors predictive of survival for hematologic malignancy patients prior to and/or early after ICU admission has been the focus of considerable research effort $[12,13,16,20,22,26,28$, 30-32,35]. Several factors have been suggested to predict non-survival at various time points across a range of studies including: older patient age [14], poor performance status [13], AML subtype [13], relapsed/refractory AML status [22], poor cytogenetic profile [16], higher illness severity or organ failure score

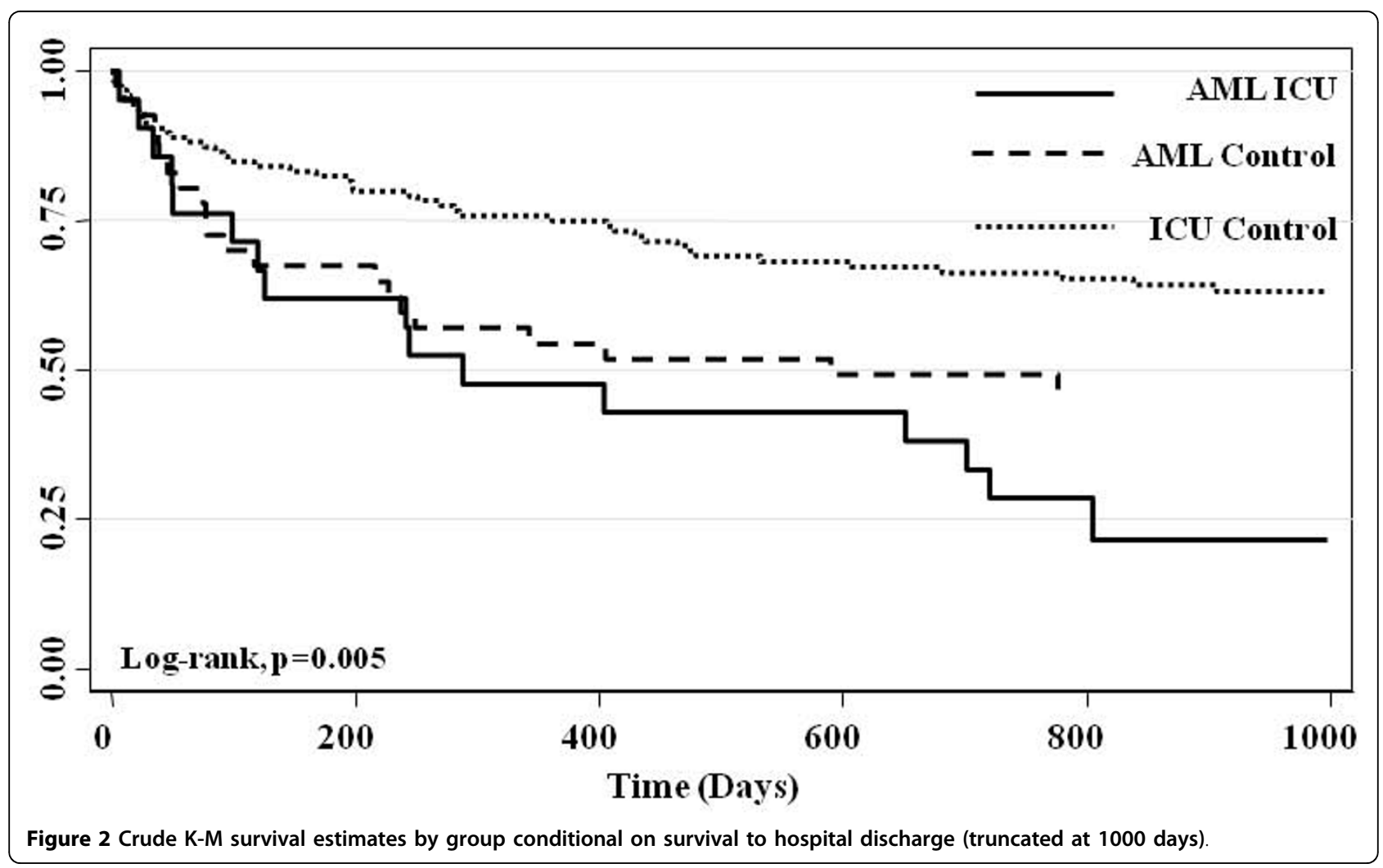


Table 6 Univariate factors associated with 90-day mortality in patients with AML

\begin{tabular}{|c|c|c|c|}
\hline \multirow[t]{2}{*}{ Characteristic } & \multicolumn{2}{|c|}{ 90-Day Status } & \multirow[t]{2}{*}{ p-value } \\
\hline & $\begin{array}{c}\text { Dead } \\
(n=25)\end{array}$ & $\begin{array}{c}\text { Alive } \\
(n=20)\end{array}$ & \\
\hline Age (mean [SD]) & $59.4(11.7)$ & $49.8(12.9)$ & 0.01 \\
\hline$\geq 2$ co-morbidities (\%) & $12(52.2)$ & $9(40.9)$ & 0.55 \\
\hline AML M1 Subtype (\%) & $12(48.0)$ & $3(15.0)$ & 0.03 \\
\hline Poor cytogenetic profile (\%) & $6(26.1)$ & $7(31.8)$ & 0.75 \\
\hline $\begin{array}{l}\text { Time from AML diagnosis } \\
\text { to ICU (d) }\end{array}$ & $65(12-288)$ & $40(9-95)$ & 0.61 \\
\hline $\begin{array}{l}\text { Relapse/refractory AML status } \\
\text { (\%) }\end{array}$ & $8(32.0)$ & $5(25.0)$ & 0.75 \\
\hline $\begin{array}{l}\text { Duration of neutropenia (d) } \\
\text { (med [IQR]) }\end{array}$ & $15(13-19)$ & $15(13-19)$ & 0.80 \\
\hline Chemotherapy in ICU (\%) & $1(4.0)$ & $6(30.0)$ & 0.03 \\
\hline Sepsis diagnosis (\%) & $8(32.0)$ & $6(33.3)$ & 1.0 \\
\hline APACHE II score (mean [SD]) & $32.4(10.7)$ & $28.0(9.5)$ & 0.15 \\
\hline SOFA score (mean [SD]) & $14.6(4.3)$ & $11.4(3.3)$ & 0.007 \\
\hline Delta SOFA (day 1) (med [IQR]) & 1 (0 to 3$)$ & 0 (-2 to 2$)$ & 0.02 \\
\hline Delta SOFA (day 3) (med [IQR]) & $2(-1$ to 4$)$ & $-2(-4$ to 2$)$ & 0.02 \\
\hline SOFA (maximum) (mean [SD]) & $12.1(5.3)$ & $10.8(3.1)$ & 0.46 \\
\hline MAP $<60 \mathrm{mmHg}(\%)$ & $11(44.0)$ & $4(22.2)$ & 0.20 \\
\hline Lactate (mmol/L) (mean [SD]) & $4.1(4.6)$ & $2.1(1.7)$ & 0.08 \\
\hline Vasoactive therapy (\%) & $22(88.0)$ & $12(60.0)$ & 0.04 \\
\hline Shock (\%) & $25(100)$ & $13(72.2)$ & 0.009 \\
\hline Platelets ( $10^{9}$ cells/L) (med [IQR]) & $17(9-37)$ & $14(10-31)$ & 0.90 \\
\hline Bilirubin $(\mu \mathrm{mol} / \mathrm{L})$ (mean $[S D])$ & $40.5(37.3)$ & $31.1(15.7)$ & 0.30 \\
\hline $\mathrm{P} / \mathrm{F}$ ratio (mean $[S D]$ ) & $116(88)$ & $149(100)$ & $<0.001$ \\
\hline Mechanical ventilation (\%) & $21(84.0)$ & $9(45.0)$ & 0.01 \\
\hline Creatinine ( $\mu \mathrm{mol} / \mathrm{L})$ (mean $[\mathrm{SD}])$ & $148(59)$ & $176(108)$ & 0.28 \\
\hline Renal replacement therapy (\%) & $7(28.0)$ & $5(25.0)$ & 1.0 \\
\hline G-CSF (\%) & $17(68.0)$ & $9(47.4)$ & 0.22 \\
\hline Corticosteroids (\%) & $13(52.0)$ & $9(47.4)$ & 1.0 \\
\hline Withdrawal of support (\%) & $16(64.0)$ & $0(0)$ & $<0.001$ \\
\hline
\end{tabular}

Abbreviations: $d$ = days; SOFA = sequential organ failure assessment; $A P A C H E=$ acute physiology and chronic health evaluation; MAP = mean arterial pressure; $\mathrm{P} / \mathrm{F}=\mathrm{PaO}_{2} / \mathrm{FiO}_{2} ; \mathrm{G}-\mathrm{CSF}=$ granulocyte colony-stimulating factor.

$[13,16,18,22,31,32]$, leukopenia [12], vasopressor therapy $[12,16,22]$, mechanical ventilation $[13,16,22]$, acute kidney injury [12], absence of bloodstream infection $[12,27]$, and fungal sepsis [32]. In our cohort, we found that older age, AML M1 subtype, higher organ failure score, the presence of shock, vasopressors therapy, and mechanical ventilation were all associated with lower survival. There was no association between survival and cytogenetic profile, therapeutic regimen or burden of co-morbid illness. However, these prognostic factors have been inconsistent and not readily reproducible, due largely to issues related to study design (i.e. small, single

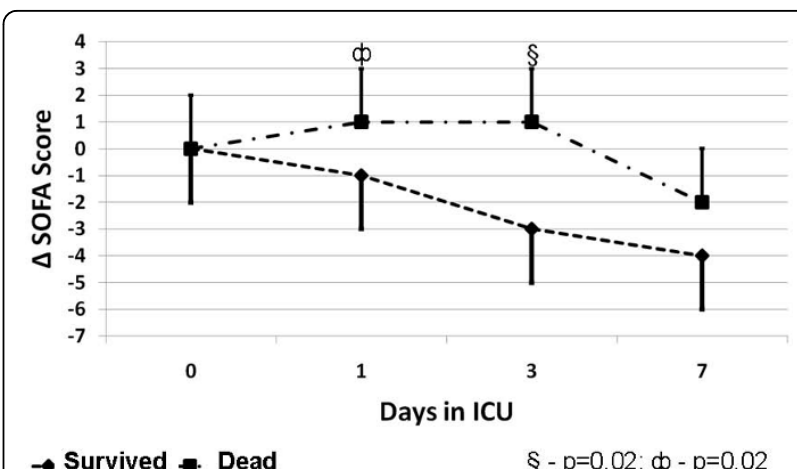

Figure $3 \Delta$ SOFA score over first 7 days in ICU stratified by $90-$ day survival.

centre, retrospective, no controls, analysis) and lack of generalizability (i.e. selection bias, mixed hematologic populations). Of note, we also found receipt of active intensive chemotherapy while in ICU was associated with higher observed survival. Recently, Vandijck et al reported that active chemotherapy was associated with better ICU survival in a cohort of 77 patients admitted to ICU with severe sepsis or septic shock [18]. These observations would suggest that prognosis for AML patients receiving active chemotherapy may be better than perceived.

Perhaps no constellation of disease or treatment-specific factors will consistently predict outcome for all AML patients developing life-threatening critical illness. As such, it may be that prognostic factors may have a limited role in the decision to admit an AML patient to ICU. Indeed, hospital survival in our study was $55.6 \%$, with $84.0 \%$ of survivors returning home and $29.9 \%$ alive at 1-year. Instead, prognostic factors may have greater relevance for decisions regarding the withholding of lifesustaining therapies and in end-of-life care. For example, worsening illness severity and/or organ dysfunction early after ICU admission has been found to predict poor clinical outcome $[11,31,32]$. Massion et al showed an improvement in Multi-Organ Dysfunction Score (MODS) of $\leq 1$ point between ICU admission and day 5 correlated with increased mortality $(81 \%$ vs. $29 \%$, p $=$ 0.001 ) [32]. Merz et al described significant higher 28day mortality for patients with worsening SOFA score over the first 48 hours (OR 24.4, 95\% CI, 8.8-67.9, p < 0.0001) [11]. Finally, Lamia et al showed worsening Simplified Acute Physiology Score (SAPS) II score, Logistic Organ Dysfunction score (LODS), and SOFA score during the first three days after ICU admission to be the best predictors of in-hospital mortality [31]. Our study further confirmed these observations. We found that the absence of change or an increase in organ failure score early after ICU admission correlated with lower survival. 
Furthermore, we found that a change in patient resuscitation status from full resuscitation to not for resuscitation (NFR) and withdrawal of active support were common and both significantly modified the observed mortality at 90 -days. In a series of 124 consecutive critically ill hematological malignancy patients, Benoit et al found $4 \%$ had a NFR order written within 24 hours of ICU admission, while $20.2 \%$ had a NFR order written after a median 7 days in ICU [12]. In our study, only $6.7 \%$ of AML ICU patients had a NFR order at presentation, whereas an additional $46.7 \%$ had their status later changed to NFR while in ICU. While we did not specifically examine the timing of this change, decisions about withholding life-sustaining measures in our study may have related to higher or worsening organ failure score and need for escalation in treatment intensity (i.e. vasoactive therapy, mechanical ventilation, RRT). We did not find association between change in resuscitation status and age, co-morbidity score, AML subtype, poor AML cytogenetic prognosis, or duration of ICU stay. We recognize one plausible explanation for this finding may relate to a clinician perception of poor clinical outcome and/or general reluctance to pursue aggressive and/or prolonged life sustaining measures for AML patients [36].

There are important limitations to our study. First, our study was single-centered and retrospective in design and was therefore potentially susceptible to bias. For example, we were unable to determine whether AML patients designated as "non-ICU" had end-of-life discussions that precluded admission to ICU, despite comparable "critical illness", which would unduly influence our incidence estimate (i.e. selection bias). However, we have attempted to minimize this by showing no significant differences in the therapeutic regiments received by AML cases and controls. Second, despite over 6 years of surveillance for AML patients admitted to our ICU, our sample was small and provided limited statistical power; we therefore omitted multi-variable analysis for determination of predictors of survival. To compensate, we further matched AML patients based on age, sex and APACHE II score (ICU only). While we did not a priori match AML groups for cytogenetic profile or therapeutic regimen received, we found no statistical differences between the AML cases and controls. Third, we endeavored to match the final cohort of AML cases with non-AML ICU controls by a ratio of $1: 5$; however, we recognize these ICU controls still represent a heterogeneous population and, despite similar illness severity, have observed differences that may impact outcome (i.e. primary diagnosis, prevalence of co-morbid illness). Finally, we were not able to ascertain additional secondary outcomes of relevance to survivors, such as health-related quality of life or functional status and the details of ongoing care requirements, which may also have prognostic significance [34].

\section{Conclusions}

In summary, AML patients may represent a minority of all critically ill admissions; however, are not uncommonly supported in ICU. These AML patients are characterized by high illness severity, multi-organ dysfunction, and high treatment intensity and have a higher risk of death when compared with matched hospitalized AML or nonAML ICU controls. Critically ill AML patients also have greater long-term mortality, which may be associated with severe clinical and disease-specific factors including absence of improvement in organ dysfunction early after ICU admission. Despite lower survival; however, our data imply a significant proportion of these critically ill AML patients survive hospitalization and are discharged home. We contend that additional multi-centre prospective studies are needed to further characterize these outcomes in AML patients suffering an episode of life-threatening critical illness.

\section{Key messages}

- Approximately 1 in 10 patients newly diagnosed with AML develop life-threatening critical illness prompting life-sustaining therapy in ICU.

- AML patients admitted to ICU have greater organ dysfunction, higher treatment intensity and use more health resources compared with matched controls.

- AML patients admitted to ICU have higher shortand long-term mortality compared with matched controls.

- Early absence of change or an increase in organ failure score following admission to ICU was associated with lower likelihood of survival for AML patients.

- Despite the higher mortality observed for AML patients admitted to ICU compared with matched controls, a significant proportion of them survive and are discharged home.

\section{Additional material}

Additional file 1: Summary of clinical studies evaluating clinical outcomes in critically ill patients with hematologic malignancies.

\footnotetext{
Abbreviations

AML: acute myelogenous leukemia; APACHE: acute physiology and chronic health evaluation; BMT: bone marrow transplantation; DNR: do not resuscitate; ICU: intensive care unit; LODS: Logistic Organ Dysfunction score; RRT: renal replacement therapy; SOFA: sequential organ failure assessment

Acknowledgements

Dr. Bagshaw is supported by a Clinical Investigator Award from the Alberta Heritage Foundation for Medical Research.
} 


\section{Author details}

'Department of Anesthesia and Pain Medicine, Faculty of Medicine and Dentistry, University of Alberta Hospital, 8440-112ST NW, Edmonton, Alberta, T6G2B7 Canada. ${ }^{2}$ Department of Medicine, Faculty of Medicine and Dentistry, University of Alberta Hospital, 8440-112ST NW, Edmonton, Alberta, T6G2B7 Canada. ${ }^{3}$ Department of Laboratory Medicine and Pathology, Faculty of Medicine and Dentistry, University of Alberta Hospital, 8440-112ST NW, Edmonton, Alberta, T6G2B7 Canada. ${ }^{4}$ Division of Critical Care Medicine, Faculty of Medicine and Dentistry, University of Alberta Hospital, 8440-112ST NW, Edmonton, Alberta, T6G2B7 Canada.

\section{Authors' contributions}

All authors read and approved the final manuscript. ALR and KC developed study protocol, obtained data, analyzed data and wrote manuscript. DRT developed study protocol, and provided critical revision of manuscript. IM developed study protocol, obtained data, analyzed data and provided critical revision of manuscript. SMB conceived the study, developed study protocol, obtained data, analyzed data and wrote and provided critical revision of manuscript.

\section{Competing interests}

The authors declare that they have no competing interests.

Received: 9 March 2010 Accepted: 28 September 2010

Published: 28 September 2010

\section{References}

1. Deschler B, Lubbert M: Acute myeloid leukemia: epidemiology and etiology. Cancer 2006, 107:2099-2107.

2. Ries LAG, Melbert D, Krapcho M: SEER Cancer Statistics Review 1975-2005. Bethesda, MD: National Cancer Institute 2008.

3. Kantarjian H, O'Brien S, Cortes J, Giles F, Faderl S, Jabbour E, GarciaManero G, Wierda W, Pierce S, Shan J, Estey E: Results of intensive chemotherapy in 998 patients age 65 years or older with acute myeloid leukemia or high-risk myelodysplastic syndrome: predictive prognostic models for outcome. Cancer 2006, 106:1090-1098.

4. Sierra J, Martino R, Sanchez B, Pinana JL, Valcarcel D, Brunet S: Hematopoietic transplantation from adult unrelated donors as treatment for acute myeloid leukemia. Bone Marrow Transplant 2008, 41:425-437.

5. Estopa R, Torres Marti A, Kastanos N, Rives A, Agusti-Vidal A, Rozman C: Acute respiratory failure in severe hematologic disorders. Crit Care Med 1984, 12:26-28.

6. Johnson MH, Gordon PW, Fitzgerald FT: Stratification of prognosis in granulocytopenic patients with hematologic malignancies using the APACHE-II severity of illness score. Crit Care Med 1986, 14:693-697.

7. Lloyd-Thomas AR, Dhaliwal HS, Lister TA, Hinds CJ: Intensive therapy for life-threatening medical complications of haematological malignancy. Intensive Care Med 1986, 12:317-324

8. Schuster DP, Marion JM: Precedents for meaningful recovery during treatment in a medical intensive care unit. Outcome in patients with hematologic malignancy. Am J Med 1983, 75:402-408.

9. Ashkenazi YJ, Kramer BS, Harman E: Short-term outcome among patients with leukemia and lymphoma admitted to a medical intensive care unit. South Med J 1986, 79:1086-1088.

10. Brunet F, Lanore JJ, Dhainaut JF, Dreyfus F, Vaxelaire JF, Nouira S, Giraud T, Armaganidis A, Monsallier JF: Is intensive care justified for patients with haematological malignancies? Intensive Care Med 1990, 16:291-297.

11. Merz TM, Schar P, Buhlmann M, Takala J, Rothen HU: Resource use and outcome in critically ill patients with hematological malignancy: a retrospective cohort study. Crit Care 2008, 12:R75.

12. Benoit DD, Vandewoude KH, Decruyenaere JM, Hoste EA, Colardyn FA: Outcome and early prognostic indicators in patients with a hematologic malignancy admitted to the intensive care unit for a life-threatening complication. Crit Care Med 2003, 31:104-112.

13. Rabbat A, Chaoui D, Montani D, Legrand O, Lefebvre A, Rio B, Roche N, Lorut C, Marie JP, Huchon G: Prognosis of patients with acute myeloid leukaemia admitted to intensive care. Br J Haematol 2005, 129:350-357.

14. Rabe C, Mey U, Paashaus M, Musch A, Tasci S, Glasmacher A, SchmidtWolf IG, Sauerbruch T, Dumoulin FL: Outcome of patients with acute myeloid leukemia and pulmonary infiltrates requiring invasive mechanical ventilation-a retrospective analysis. J Crit Care 2004, 19:29-35.
15. Scales DC, Thiruchelvam D, Kiss A, Sibbald WJ, Redelmeier DA: Intensive care outcomes in bone marrow transplant recipients: a populationbased cohort analysis. Crit Care 2008, 12:R77.

16. Thakkar SG, Fu AZ, Sweetenham JW, Mclver ZA, Mohan SR, Ramsingh G, Advani AS, Sobecks R, Rybicki L, Kalaycio M, Sekeres MA: Survival and predictors of outcome in patients with acute leukemia admitted to the intensive care unit. Cancer 2008, 112:2233-2240.

17. Tremblay LN, Hyland RH, Schouten BD, Hanly PJ: Survival of acute myelogenous leukemia patients requiring intubation/ventilatory support. Clin Invest Med 1995, 18:19-24.

18. Vandijck DM, Benoit DD, Depuydt PO, Offner FC, Blot SI, Van Tilborgh AK, Nollet J, Steel E, Noens LA, Decruyenaere JM: Impact of recent intravenous chemotherapy on outcome in severe sepsis and septic shock patients with hematological malignancies. Intensive Care Med 2008, 34:847-855.

19. Epner DE, White P, Krasnoff M, Khanduja S, Kimball KT, Knaus WA: Outcome of mechanical ventilation for adults with hematologic malignancy. $J$ Investig Med 1996, 44:254-260.

20. Lloyd-Thomas AR, Wright I, Lister TA, Hinds CJ: Prognosis of patients receiving intensive care for lifethreatening medical complications of haematological malignancy. Br Med I (Clin Res Ed) 1988, 296:1025-1029.

21. Peters SG, Meadows JA, Gracey DR: Outcome of respiratory failure in hematologic malignancy. Chest 1988, 94:99-102.

22. Park HY, Suh GY, Jeon K, Koh WJ, Chung MP, Kim H, Kwon OJ, Kim K, Jang JH, Jung CW, et al: Outcome and prognostic factors of patients with acute leukemia admitted to the intensive care unit for septic shock. Leuk Lymphoma 2008, 49:1929-1934.

23. Vardiman JW, Thiele J, Arber DA, Brunning RD, Borowitz MJ, Porwit A, Harris NL, Le Beau MM, Hellstrom-Lindberg E, Tefferi A, Bloomfield CD: The 2008 revision of the World Health Organization (WHO) classification of myeloid neoplasms and acute leukemia: rationale and important changes. Blood 2009, 114:937-951.

24. Knaus WA, Draper EA, Wagner DP, Zimmerman JE: APACHE II: a severity of disease classification system. Crit Care Med 1985, 13:818-829.

25. Vincent JL, Moreno R, Takala J, Willatts S, De Mendonca A, Bruining $H$, Reinhart K, Suter PM, Thijs LG: The SOFA (Sepsis-related Organ Failure Assessment) score to describe organ dysfunction/failure. Intensive Care Med 1996, 22:707-710.

26. Cornet AD, Issa Al, van de Loosdrecht AA, Ossenkoppele GJ, Strack van Schijndel RJ, Groeneveld AB: Sequential organ failure predicts mortality of patients with a haematological malignancy needing intensive care. Eur $J$ Haematol 2005, 74:511-516.

27. Depuydt PO, Benoit DD, Vandewoude KH, Decruyenaere $\mathrm{JM}$, Colardyn FA: Outcome in noninvasively and invasively ventilated hematologic patients with acute respiratory failure. Chest 2004, 126:1299-1306.

28. Evison J, Rickenbacher P, Ritz R, Gratwohl A, Haberthur C, Elsasser S, Passweg JR: Intensive care unit admission in patients with haematological disease: incidence, outcome and prognostic factors. Swiss Med Wkly 2001, 131:681-686.

29. Ewig S, Torres A, Riquelme R, El-Ebiary M, Rovira M, Carreras E, Rano A, Xaubet A: Pulmonary complications in patients with haematological malignancies treated at a respiratory ICU. Eur Respir J 1998, 12:116-122

30. Kroschinsky F, Weise M, Illmer T, Haenel M, Bornhaeuser M, Hoeffken G, Ehninger $\mathrm{G}$, Schuler $\mathrm{U}$ : Outcome and prognostic features of intensive care unit treatment in patients with hematological malignancies. Intensive Care Med 2002, 28:1294-1300.

31. Lamia B, Hellot MF, Girault C, Tamion F, Dachraoui F, Lenain P, Bonmarchand $\mathrm{G}$ : Changes in severity and organ failure scores as prognostic factors in onco-hematological malignancy patients admitted to the ICU. Intensive Care Med 2006, 32:1560-1568.

32. Massion PB, Dive AM, Doyen C, Bulpa P, Jamart J, Bosly A, Installe E: Prognosis of hematologic malignancies does not predict intensive care unit mortality. Crit Care Med 2002, 30:2260-2270.

33. Silfvast $T$, Pettila $V$, Ihalainen $A$, Elonen $E$ : Multiple organ failure and outcome of critically ill patients with haematological malignancy. Acta Anaesthesiol Scand 2003, 47:301-306.

34. Yau $E$, Rohatiner $A Z$, Lister $T A$, Hinds $C J$ : Long term prognosis and quality of life following intensive care for life-threatening complications of haematological malignancy. Br J Cancer 1991, 64:938-942.

35. Cherif $H$, Martling $C R$, Hansen J, Kalin M, Bjorkholm M: Predictors of short and long-term outcome in patients with hematological disorders 
admitted to the intensive care unit for a life-threatening complication. Support Care Cancer 2007, 15:1393-1398.

36. Hill QA: Intensify, resuscitate or palliate: Decision making in the critically ill patient with haematological malignancy. Blood Rev 2010, 24:17-25.

\section{Pre-publication history}

The pre-publication history for this paper can be accessed here: http://www.biomedcentral.com/1471-2407/10/516/prepub

doi:10.1186/1471-2407-10-516

Cite this article as: Roze des Ordons et al:: Clinical characteristics and outcomes of patients with acute myelogenous leukemia admitted to intensive care: a case-control study. BMC Cancer 2010 10:516.

Submit your next manuscript to BioMed Central and take full advantage of:

- Convenient online submission

- Thorough peer review

- No space constraints or color figure charges

- Immediate publication on acceptance

- Inclusion in PubMed, CAS, Scopus and Google Scholar

- Research which is freely available for redistribution

Submit your manuscript at www.biomedcentral.com/submit 